\title{
A blueprint for quality
}

\author{
Mark R Borgaonkar MD MSc
}

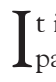

t is clear that enhancing the quality of endoscopic services improves patient outcomes. Benefits include shorter wait times, more appropriate screening and surveillance intervals, higher adenoma detection rates and fewer interval (or missed) cancers (1).

The move toward quality improvement in endoscopy originated in the United Kingdom (UK) but has become a worldwide phenomenon. It began in 2004, when a national audit of colonoscopy practice in the UK revealed much worse outcomes than expected (2). This led to the development of the Global Rating Scale (GRS) - a national program implemented by individual endoscopy units to address clinical parameters of quality and patient concerns. The GRS has been an overwhelming success, with markedly improved outcomes in all areas including higher cecal intubation rates, higher adenoma detection rates and a reduction in endoscopic complications (3).

In the current issue of the Canadian Journal of Gastroenterology, MacIntosh et al (4) (pages 74-82) report on the development of a Canadian version of the GRS (GRS-C). The project was a component of the larger Canadian Association of Gastroenterology consensus group on quality and safety in endoscopy. A working group modified the UK-GRS with the assistance of other experts in the field, including the original developers of the UK-GRS and six gastrointestinal endoscopy units throughout Canada that had been using the UK-GRS. Feedback from all sources was incorporated to revise the UK-GRS into a tool appropriate for Canadian endoscopy.

The result is a comprehensive document that sets specific standards across 12 items grouped into one of two dimensions: clinical quality and the quality of the patient experience. Each item is graded on one of four levels ( $D$ through $A$ ) defined by statements that specify the requirements of endoscopy units. To achieve higher levels on the GRS-C, units must not only engage in basic data gathering but also respond to what is found and then assess the response to any changes made. Units can complete the GRS-C at their convenience on a web portal to document their activities and receive their grade. The authors have also created a number of web-based materials available to units to facilitate the implementation of the GRS-C.

Although this is a very important achievement for endoscopic service provision in Canada, it is just the first step. The responsibility now lies with endoscopists and the units in which they work to embrace and implement this initiative. Undoubtedly, there will be challenges. Some will question the benefits of the GRS-C and the necessity to implement it at all. Physicians may feel reluctant about having aspects of their individual endoscopic performance recorded and reviewed. Other staff may believe that the GRS-C needlessly increases their workload. Hospital administrators may balk at the costs of implementing the GRS-C, such as those of starting an electronic reporting system for endoscopic procedures.

Such concerns are to be expected. However, the value of the GRS-C will quickly become apparent. The success of the GRS in the UK has been dramatic and there is every reason to expect similar results here in Canada. Until we implement the GRS-C and commit to applying it whole-heartedly, we will not reap its benefits.

The past several decades have witnessed numerous improvements in endoscopic technology that have enhanced patient care and captured the imagination of endoscopists. However, improving the quality of gastrointestinal endoscopy has the potential to have a more profound and far-reaching impact than any technological advance. Some may doubt that recording bowel preparation scores or adenoma detection rates could have a greater effect than cutting-edge technology. Yet, consider that even advanced imaging cannot compensate for a colon that is insufficiently cleansed or examined too quickly.

The authors of the GRS-C have provided us with a blueprint for high-quality endoscopic service provision in Canada. All of the important areas are covered in detail with specific points to guide our improvement. Moreover, the web-based resources will provide great assistance to units by saving time and making the changes easier to implement. We have no more excuses. The time for endoscopic quality improvement in Canada is now.

\section{REFERENCES}

1. Kaminski MF, Regula J, Kraszewska E, et al. Quality indicators for colonoscopy and the risk of interval cancer. N Engl J Med 2010;362:1795-803.

2. Bowles CJ, Leicester R, Romaya C, Sawrbrick E, Williams CB, Epstein O. A prospective study of colonoscopy practice in the UK today: Are we adequately prepared for national colon cancer screening tomorrow? Gut 2004;53:277-83.

3. Gavin DR, Valori RM, Anderson JT, Donnelly MT, Williams JG, Sawrbrick ET. The national colonoscopy audit: A nationwide assessment of quality and safety of colonoscopy in the UK. Gut 2012; June 1 (Epub ahead of print).

4. MacIntosh D, Dude C, Hollingworth R, Veldhuyzen van Zanten S, Daniels S, Ghattas G. The endoscopy Global Rating Scale Canada: Development and implementation of a quality improvement tool. Can J Gastroenterol 2013:27:74-82. 


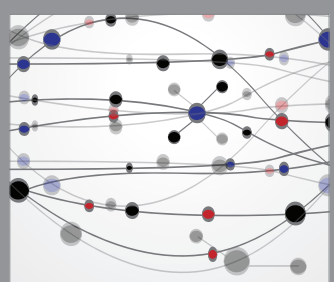

The Scientific World Journal
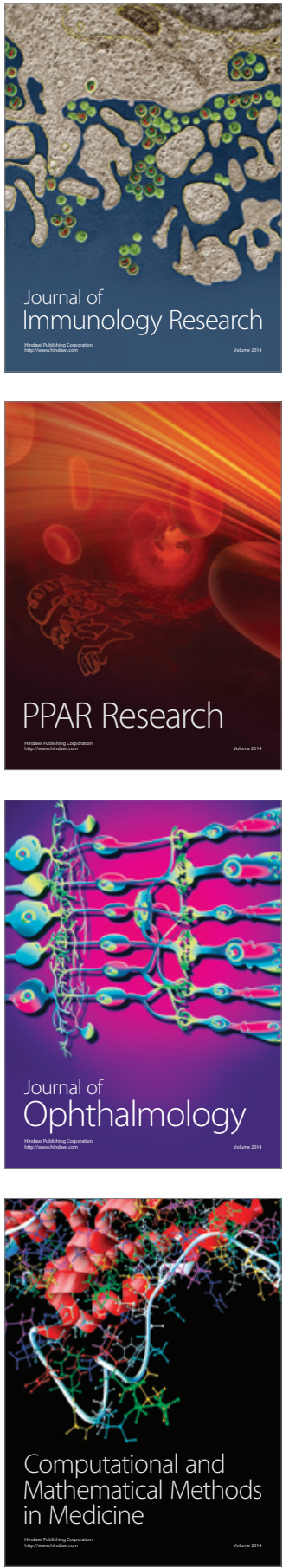

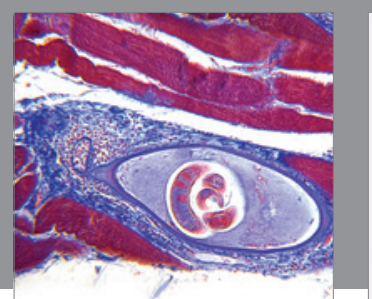

Gastroenterology Research and Practice

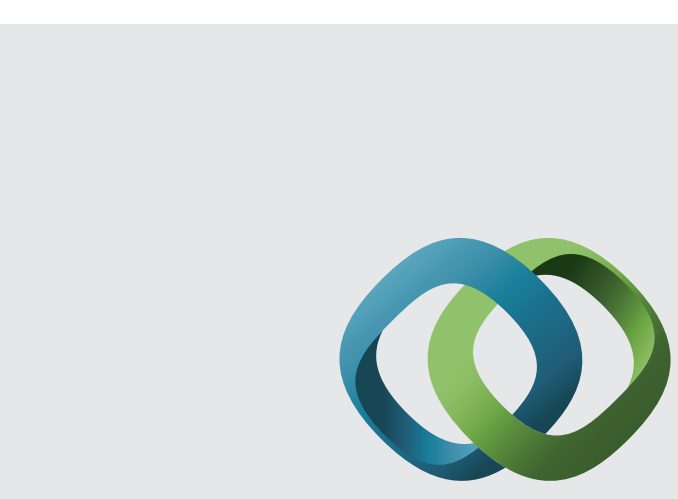

\section{Hindawi}

Submit your manuscripts at

http://www.hindawi.com
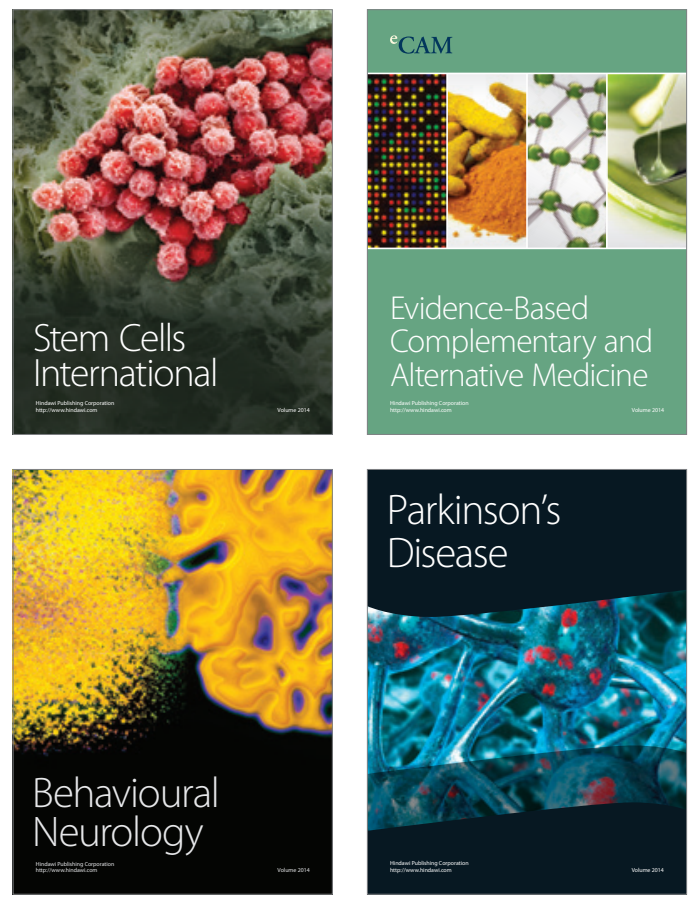
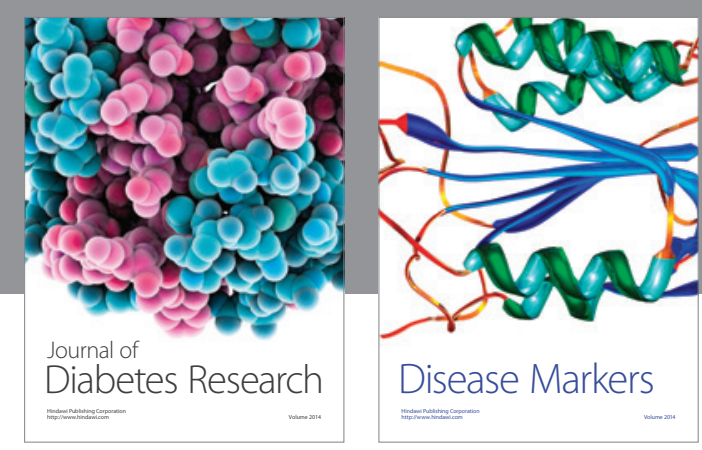

Disease Markers
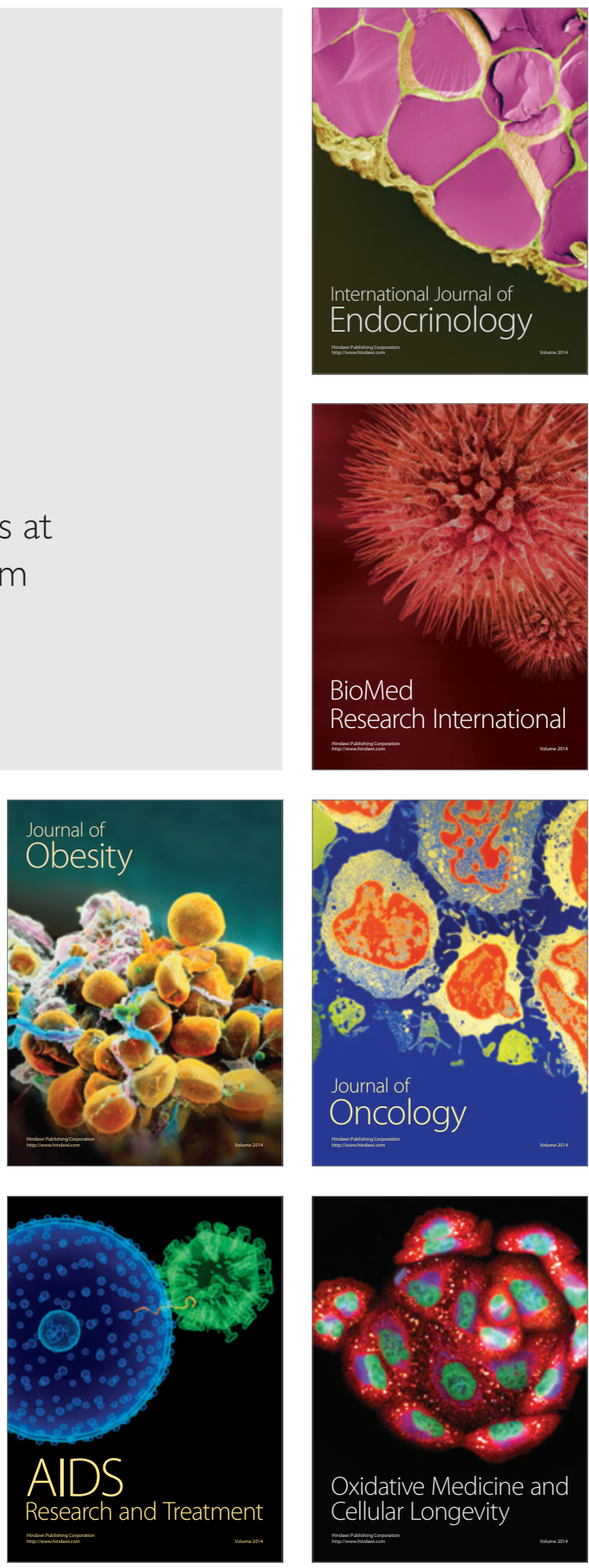